\title{
Faktor dan Kendala dalam Penerapan Kurikulum Prodi Pendidikan Bahasa Jerman Universitas Negeri Malang di Era Revolusi Industri 4.0
}

\author{
Dewi Kartika Ardiyani \\ Dosen Prodi S1 Pendidikan Bahasa Jerman, Universitas Negeri Malang \\ Jl. Semarang No.5, Sumbersari, Kec. Lowokwaru, Kota Malang, Jawa Timur, \\ Indonesia \\ Email: dewi.kartika.fs@um.ac.id
}

\begin{tabular}{l}
\hline Tersedia Online di \\
\hline http://www.jurnal.unublitar.ac.id// \\
index.php/briliant \\
\hline
\end{tabular}

\begin{tabular}{l}
\hline Sejarah Artikel \\
\hline Diterima pada Mei 2021 \\
Disetuji pada Mei 2021 \\
Dipublikasikan pada Mei 2021 \\
Hal. 232-240 \\
\hline
\end{tabular}

\begin{tabular}{l}
\hline Kata Kunci: \\
\hline Standar berbahasa Jerman; \\
Zertifikat Deutsch B1; Prodi \\
Pendidikan Bahasa Jerman
\end{tabular}

\section{DOI:}

http://dx.doi.org/10.28926/briliant .v3i4.649

\begin{abstract}
Abstrak: Penelitian kualitatif ini bertujuan mendeskripsikan faktor dan kendala dalam penerapan kurikulum yang telah dikembangkan oleh Prodi S1 Pendidikan Bahasa Jerman (PSPBJ) Universitas Negeri Malang dalam meningkatkan kompetensi lulusan sesuai dengan standar dan kebutuhan masyarakat di era globalisasi dan revolusi industi 4.0. Beberapa faktor yang menjadi kendala dalam implementasi kurikulum antara lain standar kebahasaan, pengembangan kurikulum yang terlalu menekankan pada konsep/teori, kurangnya riset untuk menganalisis kebutuhan pasar dan mahasiswa, kualitas dosen, dan belum adanya benchmarking. Untuk mengatasi kendala tersebut, dipaparkan beberapa pendapat dan saran berdasarkan hasil diskusi forum dan angket oleh pemangku kepentingan yang perlu diperhatikan untuk meningkatkan kualitas lulusan PSPBJ.
\end{abstract}

\section{PENDAHULUAN}

Di era globalisasi dan revolusi industri 4.0, peranan guru mendapat tantangan agar dapat memiliki kemampuan mengajar dan mengelola kegiatan belajar mengajar sesuai dengan kondisi dan kebutuhan peserta didik saat ini. Oleh sebab itu guru diharuskan dapat menjalin komunikasi yang baik dengan peserta didik dan masyarakat, serta dapat menguasai teknologi guna peningkatan kualitas pembelajaran (Ardiyani dan Kurniawan, 2019). Pencapaian kemampuan profesional seorang guru tidak hanya menjadi tanggung jawab guru tersebut, lembaga-lembaga di bawah naungan Departemen Pendidikan dan Kebudayaan (Depdiknas) seperti P4TK, melainkan juga menjadi tanggung jawab universitas yang telah mencetak calon guru tersebut. Seperti yang dikemukakan oleh Andriani (2010) bahwa peningkatan profesionalan guru dapat dilakukan melalui pembimbingan dan penyiapan yang baik dan terencana, salah satunya adalah melalui kurikulum yang akan diterapkan.

Saat ini standar kelulusan prodi S1 Bahasa Jerman di Indonesia mendapat tantangan dari masyarakat. Kebutuhan guru bahasa Jerman dengan standar minimal 
bahasa Jerman tingkat B1 standar internasional yang dibuktikan dengan kepemilikan sertifikat ujian Zertifikat Deutsch (ZD) telah ditetapkan Goethe Institut Indonesia melalui kontrak kerjasama antara prodi pendidikan bahasa Jerman, universitas eks LPTK, Goethe Institut dan Kemenristekdikti pada tahun 2018. Standar kemampuan bahasa tingkat B1 versi standar kebahasaan Eropa Common European Framwork of Languanges biasa disingkat CEFR, juga dipersyaratkan menjadi standar minimal guru bahasa Jerman oleh Pusat Pusat pengembangan dan Pemberdayaan Pendidik dan tenaga Kependidikan (P4TK) bahasa Jakarta. Hal tersebut tertuang di dalam Ujian Kompetensi Guru (UKG) yang mensyaratkan guru bahasa Jerman Indonesia berada pada tingkat minimal B1.

Standar kemampuan berbahasa Eropa dibagi menjadi 6 tingkatan yaitu, tingkat A1, A2, B1, B2, C1, dan C2. Di setiap akhir dari tingkatan ditutup dengan ujian bersertifikat internasional yang diadakan oleh berbagai lembaga diantaranya /yang diakui secara internasional adalah sertifikat Goethe Institut. Kemampuan dasar akhir berbahasa Jerman seseorang adalah dengan pembuktian kepemilikan sertifikat kelulusan ujian tingkat B1 yang terdiri dari empat modul keterampilan berbahasa dengan nilai minimal kelulusan untuk masing-masing modul adalah 60 (Storc \& Eichheim, 2010).

Kemampuan bahasa Jerman setingkat B1 standar CEFR merupakan kompetensi berbahasa reseptif, produktif, dan interaktif. Ketiga kemampuan tersebut terintegrasi di dalam dari empat keterampilan berbahasa; yaitu membaca, menulis, mendengar, dan berbicara Glaboniat (2005). Kemampuan reseptif tertulis yang harus dikuasai mahasiswa adalah pemahaman teks sederhana yang berhubungan dengan tema kehidupan sehari-hari. Kemampuan produktif tertulis mencakup kemampuan menulis tema kehidupan sehari-hari, merangkum teks sederhana atau kutipan, menulis teks yang terstruktur berdasarkan tema yang telah dipelajari, dan menggunakan bermacam-macam ungkapan sederhana dengan fleksibel untuk mengungkapkan apa yang ingin disampaikan.

Sesuai Katalog Jurusan Sastra Jerman Universitas Negeri Malang tahun 2018 dinyatakan bahwa penguasaan lulusan mahasiswa Sastra Jerman Universitas Negeri Malang disyaratkan minimal memiliki kemampuan bahasa Jerman standar B1 standar CEFR. Pada akhir semester IV, mahasiswa wajib untuk mengikuti dan lulus ujian standar kebahasaan tingkat B1 standar CEFR dalam ujian Zertifikat Deutsch B1 yang diselenggarakan oleh Goethe Institut. Sementara itu, sebagai perbandingan, struktur kurikulum Program Studi Pendidikan Bahasa Jerman di Hanoi Unversity mendukung pemerolehan bahasa Jerman secara intensif pada semester satu sampai empat. Setelah semester empat mahasiswa sudah menguasai behasa Jerman pada tingkat B1 standar CEFR, dan dilanjutkan dengan bahasa Jerman tingkat B2. Dengan demikian mahasiswa dapat menguasai bahasa Jerman pada tingkat B2 pada akhir semester empat (Nga, 2013). Dengan demikian pada semester lima dan seterusnya mahasiswa dapat mengembangkan kemampuan bahasa Jerman di tingkat $\mathrm{C} 1$ dan menggunakan bahasa Jerman secara reseptif dan produktif pada semua mata kuliah yang disajikan, baik mata kuliah kebahasaan maupun mata kuliah metodik didaktik.

Untuk menjawab tantangan tersebut di atas, PSPBJ UM melakukan analisis dan pengembanganan kurikulum. Rancangan kurikulum abad 21 disesuaikan 
dengan tujuan agar pendidikan tinggi dapat mencetak lulusan siap kerja. Pada abad 21, perguruan tinggi yang mencetak tenaga kerja harus mempertimbangkan pembelajaran sepanjang hayat guna penyiapan masa depan dan kebutuhan sosial lulusan (Bosanquet, Winchester-Seeto, dan Rowe, 2010). Correia (2014) menyatakan bahwa pendekatan kurikulum yang berorientasi pekerjaan dapat memberi ruang peserta didik berperan sebagai mitra kerja, baik untuk perusahaan ataupun lapangan kerja yang lainnya

Kurikulum yang diacu oleh program studi S-1 pendidikan bahasa Jerman di Indonesia adalah kurikulum berbasis KKNI. Kurikulum KKNI merupakan "kerangka penjenjangan kualifikasi kompetensi yang dapat menyandingkan, menyetarakan, dan mengintegrasikan antara bidang pendidikan dan bidang pelatihan kerja serta pengalaman kerja dalam rangka pemberian pengakuan kompetensi kerja sesuai dengan struktur pekerjaan di berbagai sektor" (perpres no 8 tahun 2012). Posedur pengembangan kurikulum PSPBJ disusun dengan merujuk kepada Panduan Pengembangan Kurikulum Berbasis Kompetensi Pendidikan Tinggi yang dikeluarkan oleh Direktorat Akademik Direktorat Jenderal Pendidikan Tinggi Tahun 2008 dan Pedoman 7 Pengembangan Kurikulum LPTK (Dikti, 2012, Ardiyani \& Kurniawan, 2019).

Pengembangan dan revisi kurikulum yang telah dilakukan oleh PSPBJ UM sudah melalui prosedur pengembangan kurikulum dengan memperhatikan prinsipprinsipnya. Seperti yang dinyatakan oleh Hamalik $(2006$; 2007) bahwa untuk pengembangan atau revisi kurikulum harus memperhatikan beberapa hal berikut ini. (1) Bagaimana cara artikulasi atau pertautan kurikulum dengan elemen-elemen pendidikan yang terkait. (2) Kapan kurikulum akan direvisi. (3) Informasiinformasi yang dibutuhkan dan sumber-sumber yang dapat digunakan untuk bahan revisi kurikulum. (4) Pihak-pihak yang terlibat dalam revisi kurikulum. (5) Langkah-langkah yang dilakukan dalam kegiatan revisi kurikulum. (6) Cara yang digunakan untuk melakukan revisi kurikulum. Setelah melalui semua proses tersebut, muncul beberapa faktor yang menjad kendala bagi PSPBJ UM dalam mengimplementasikan kurikulum tersebut.

Penelitian tentang kurikulum telah dilakukan oleh Manyukhina (2019). Manyukhina melakukan penelitian analisis konten dokumen kurikulum di dalam tabel komparatif kurikulum di negara Inggris, Australia, Hong-Kong, dan Kanada. Penelitian bertujuan untuk mengetahui bagaimana tipologi baru pada pengembangan kurikulum. Hasil penelitian menunjukkan bahwa kurikulum seharusnya memperhatikan kebutuhan pembelajar sebagai agen pembelajaran. Agen pembelajaran sendiri di beberapa negara dipahami sebagai kemampuan untuk bertindak secara independen dan membuat pilihan sendiri. Hal tersebut dianggap sebagai inti dari pembelajaran. Dengan demikian, kurikulum pendidikan memiliki peran dalam pengembangan agen pembelajar. Sementara pengembangan konten kurikulum sebagai fokus utama dalam pendidikan, penelitian, dan kebijakan belum berimplikasi pada pembelajar sebagai agen perubahan. Penelitian ini memberikan gambaran dan landasan teoritis bagaimana penyusunan kurikulum mengeksploitasi potensi pembelajar sebagai agen pembelajaran dan perubahan.

Widodo (2013) menyampaikan di dalam makalahnya bahwa terdapat fakta tentang pembelajaran bahasa Jerman di Indonesia, karena bahasa Jerman menawarkan akses penting untuk ilmu pengetahuan dan teknologi. Artikel 
memberikan gambaran tentang situasi pembelajaran bahasa Jerman di program studi di Indonesia untuk digunakan sebagai pertukaran pengalaman pada relevansi praktis dari pembelajaran bahasa Jerman di wilayah Asia Tenggara. Kurikulum di prodi bahasa Jerman di Indonesia sebaiknya mengikuti perkembangan yang terjadi di masyarakat. Kompetensi tambahan yang disiapkan oleh prodi tidak hanya terbatas pada kompetensi utama lulusan. Hal tersebut dapat dibuktikan melalui kebutuhan akan penggunaan bahasa Jerman di Indonesia seiring dengan perkembangan Pariwisata sejak 1980-an sampai saat ini. Kebutuhan tenaga kerja yang kompeten di Hotel dan sektor pariwisata. Misalnya munculnya wisatawan yang berkunjung ke Indonesia telah memberikan perspektif baru di Indonesia pada prodi pendidikan bahasa Jerman. Dengan demikian kebutuhan akan lulusan prodi pendidikan bahasa Jerman saat ini berkembang sesuai dengan tuntutan kehidupan masyarakat. Oleh sebab itu kurikulum prodi pendidikan bahasa Jerman di Indonesia harus menyesuaikan keadaan tersebut.

Penelitian mengenai kemampuan bahasa Jerman guru-guru bahasa Jerman di Malang raya juga telah dilakukan oleh Hidayat (2012). Hasil penelitian menyebutkan bahwa kemampuan guru-guru bahasa Jerman yang juga alumni PSPBM baik dari universitas Negeri Malang maupun universitas eks LPTK lainnya berada pada tingkatan yang beragam mulai dari A2 dan B1, dan pada saat ini beberapa orang guru sudah berada pada tingkat B2. Rata-rata kepemilikan sertifikat B1 dan B2 mereka tidak didapatkan dari perguruan tinggi tempat mereka belajar, melainkan melalui pelatihan untuk guru yang diadakan oleh baik Goethe Institut Indonesien maupun P4TK bahasa Jakarta.

Penelitian mengenai penerapan kurikulum berbasis KKNI di perguruan tinggi juga banyak dilakukan di Indonesia. Khairiah (2015) melakukan penelitian pengena peningkatan mutu pendidikan di IAIN Bengkulu yang menggunakan kurikulum berbasis KKNI. Menurut khairiah, Peningkatan mutu perguruan tinggi dipengaruhi oleh implementasi/penerapan kurikulum KKNI melalui tiga faktor utama yaitu (1) Kecukupan sumber- sumber pendidikan dalam arti kualitas tenaga kependidikan, biaya dan sarana belajar; (2) Mutu proses belajar mengajar yang mendorong siswa belajar efektif; dan (3) Mutu keluaran dalam bentuk pengetahuan, dan sikap keterampilan. Dapat direkomendasikan kepada seluruh perguruan tinggi hendaknya segera mengimplementasi kurikulum berbasis KKNI dan kepada pemerintah hendaknya mengalokasikan dana yang imbang kepada PTKIN untuk implementasi kurikulum berbasis KKNI dalam upaya peningkatan mutu pendidikan PTKIN. Di kota yang sama, Jono, AA (2016) melakukan penelitian yang sama pula pada Program Studi Bahasa Inggris di seluruh Lembaga Penyelenggara Pendidikan (LPTK) yang ada. Kendala dalam pengimplementasian kurikulum berbasis KKNI Prodi Pendidikan Bahasa Inggris pada masing-masing LPTK adalah belum memiliki panduan tertulis bersifat mandiri tentang mekanisme dan prosedur yang berisikan kebijakan pengembangan kurikulum.Sementara dalam penelitian Siagian, BA., dan Siregar, GNS., (2018) penerapan kurikulum berbasis KKNI di Universitas Negeri Medan sudah dikatakan baik, meskipun masih perlu perbaikan pada beberapa aspek syang menjadi kendala dalam penerapannya eperti kesiapan dosen, kelengkapan sarana dan prasarana, ketersediaan mitra magang, dan tentunya kesiapan mahasiswa. Ketiga penelitian tersebut memiliki ranah yang sama dengan 
penelitian ini. Perbedaannya adalah penelitian ini secara khusus mendeskripsikan kendala yang ditemui Prodi S1 Pendidikan Bahasa Jerman di Universitas Negeri Malang dalam mengimplementasikan kurikulum berbasis KKNI yang dikembangkan guna meningkatkan kompetensi lulusan sesuai dengan standar dan kebutuhan masyarakat saat ini.

\section{METODE}

Penelitian yang dilakukan di Universitas Negeri Malang dan P4TK Bahasa Jakarta ini menggunakan pendekatan penelitian kualitatif. Jenis data yang dihasilkan dalam penelitian ini adalah berupa data kualitatif berupa (1) hasil diskusi kelompok terarah Focus Group Discussion (FGD) dengan tim widiaiswara bahasa Jerman P4TK bahasa Jakarta untuk mengetahui kendala yang dihadapi guru-guru bahasa Jerman sebagai lulusan dari prodi S1 pendidikan bahasa Jerman dan (2) hasil angket oleh stakeholder yaitu konsultan pendidikan dari Bildungskooperation Deutsch GoetheI Institut Indonesien. FGD dilaksanakan pada tanggal 17 dan 18 Agustus 2019 bertempat PPP4TK Bahasa Jakarta. Diskusi dihadiri oleh Tim peneliti dan Dra. Emy Widiarti selaku widiaiswara bahasa Jerman PPP4TK Bahasa.

Sumber data penelitian adalah widiaiswara bahasa Jerman dari P4TK bahasa Jakarta. Sumber data berperan sebagai ahli yang menganalisis dokumen kurikulum PSPBJ UM dan menjadi narasumber dalam diskusi kelompok terarah mengenai kendala-kendala dalam penerapannya. Sumber data berikutnya adalah konsultan pendidikan dari Bildungskooperation Deutsch Goethe Institut Indonesien yang berperan memberi gambaran kebutuhan pemangku kepentingan paling aktual dan memberikan saran.

Data hasil diskusi kelompok terarah dan hasil angket dianalisis dengan berdasarkan laporan diskusi dengan langkah-langkah sebagai berikut. (1) Membuat berita acara FGD. (2) Mengumpulkan jawaban-jawaban dan saran narasumber dari hasil FGD sebagai data yang digunaan untuk menjawab rumusan masalah penelitian. (3) Mengelompokkan pendapat menurut masalah atau topik yang relevan. Melalui angket yang diberikan kepada stakeholder dari konsultan pendidikan Bildungskooperationsdeutsch Goethe Indtitut Indonesien diperoleh data-data mengenai faktor-faktor yang harus diperhatikan agar PSPBJ dapat mengatasi kendala dalam menentukan standar kebahasaan lulusannya sesuai dengan tuntutan yang dihadapi lulusan di masyarakat.

\section{HASIL DAN PEMBAHASAN}

Pengembangan kurikulum mengacu pada pada kurikulum yang berlaku di perguruan tinggi di Indonesia yaitu standar Kerangka Kualifikasi Nasional Indonesia [KKNI]. Sebagai implikasi dari pemberlakuan kurikulum yang mengacu pada KKNI, setiap program studi seharusnya berpacu untuk menghasilkan lulusan dengan kualifikasi sesuai standar yang diinginkan. Berkaitan dengan itu, PSPBJ UM melakukan perbaikan dan pengembangan kurikulum agar dapat menghasilkan lulusan yang sesuai dengan tuntutan masyarakat di era revolusi global. Namun demikian, muncul faktor-faktor yang menjadi kendala dalam mengimplementasikan kurikulum tersebut. 
Berdasarkan hasil diskusi melalui Forum Group Discussion (FGD) tim peneliti dengan widiaiswara PPPTK bahasa, berikut faktor yang dapat menjadi kendala dalam mengimplementasikan kurikulum PSPBJ UM: (1) Standar bahasa Jerman tingkat B1 belum dilaksanakan sepenuhnya, sehingga belum semua lulusan mempunyai sertifikat bahasa Jerman tingkat B1. (2) Pengembangan kurikulum pedagogik lebih banyak menekankan pada teori/konsep. (3) Kurangnya riset-riset sebagai dasar untuk menganalisis kebutuhan pasar dan mahasiswa. (4) Kualitas dosen, khususnya di bidang ICT (5) Belum adanya benchmarking di bidang Deutsch als Fremdsprache.

Standar yang dipakai oleh PSPBJ adalah CEFR minimal tingkat B1 (Glaboniat, 2005; Storc \& Eichheim, 2010; Katalog PSPBJ, 2018). Seharusnya kompetensi lulusan PSPBJ mengacu pada standar tersebut, tapi pada kenyataannya standar bahasa Jerman tingkat B1 belum dilaksanakan sepenuhnya, sehingga belum semua lulusan mempunyai sertifikat bahasa Jerman tingkat B1. Untuk permasalahan itu, PSPBJ disarankan untuk konsisten dalam menerapkan standar berdasarkan CEFR. Untuk kualifikasi menjadi guru bahasa Jerman di Indonesia minimal B1 dengan catatan sebaiknya dengan predikat minimal yang awalnya "cukup" ditingkatkan menjadi "baik".

Untuk bersaing di dunia kerja (dalam hal ini persaingan dunia/industri kerja secara global), stakeholder dari konsultan pendidikan Bildungskooperationsdeutsch Goethe Indtitut Indonesien menyarankan sebaiknya kualifikasi tingkat kebahasaan lulusan prodi Bahasa Jerman minimal adalah B2 dan lebih baik di $\mathrm{C} 1$ supaya bisa mampu bersaing di dunia kerja global. Tingkat B1 dianggap masih dianggap belum cukup untuk bersaing di dunia kerja saat ini, sebagai pembanding, standar kemampuan bahasa lulusan Hanoi University adalah tingkat C1 (Nga, 2013). Lebih lanjut stakeholder menyatakan bahwa mahasiswa yang memulai kuliah di jurusan bahasa Jerman harus sudah dengan kemampuan level A2, sehingga kemampuan bahasa mereka bisa diteruskan ke jenjang berikutnya, setelah dua semester mahasiswa sudah mempunya level B1. Jika hal tesebut dapat dilakukan, maka mata kuliah kelompok metodik didaktik bisa disajikan dalam bahasa Jerman dan pada akhirnya semua mahasiswa dapat mencapai tingkat B2.

Stakeholder juga memberikan saran-saran yang dapat digunakan PSPBJ UM untuk meningkatkan kualitas lulusannya yaitu melalui kemampuan bahasa Jerman tingkat B2 agar lulusan dapat bersaing tidak hanya di tingkat nasional melainkan di tingkat internasional. Untuk mempercepat penguasaan bahasa Jerman mahasiswa, perlu diadakan pembiasaan mempraktikkan bahasa Jerman melalui kewajiban berbahasa Jerman selama di berada di lingkungan kampus. Untuk itu silabus perkuliahan atau kebijakan prodi seharusnya mengakomodir sistem tersebut agar kegiatan berbahasa Jerman sehari-hari menjadi tradisi di prodi.

Kualitas dan hasil pembelajaran bahasa Jerman lulusan S1 PSBJ dapat diukur melalui ujian standardisasi sesuai standar CEFR. Sebagaimana standar bahasa Jerman minimal bagi lulusan program studi S-1 bahasa Jerman di Indonesia, yaitu tingkat B1, maka seluruh lulusan harus memiliki minimal sertifikat ujian bahasa Jerman tingkat B1 [Zertifikat Deutsch]. Untuk meningkakan kualitas dan memenuhi tantangan masyarakat era 4.0, standar nilai ujian bahasa Jerman tingkat 
B1 mahasiswa [Zertifikat Deutsch] di Indonesia perlu ditingkatkan dari "cukup" menjadi "baik" dan selanjutnya dapat ditingkatkan ke tingkat B2 bahkan C1. Dengan demikian, PSPBJ dapat menghasilkan lulusan yang berkompeten dan profesional seperti yang dikemukakan oleh Andriani (2010) bahwa untuk menjadikan guru yang profesional diperlukan pembimbingan dan penyiapan yang baik dan terencana. Dengan perencanaan dan pembimbingan yang baik di perguruan tinggi masing-masing, perguruan tinggi akan menghasilkan calon-calon guru yang profesional.

Kurikulum pedagogik yang lebih banyak menekankan pada teori/konsep juga menjadi kendala dalam implementasi kurikulum di PSPBJ UM. Menurut Bosanquet, Winchester-Seeto, dan Rowe (2010), perguruan tinggi di revolusi industri 4.0 harus mencetak tenaga kerja sehingga harus mempertimbangkan pembelajaran sepanjang hayat guna penyiapan masa depan dan kebutuhan sosial lulusan. Untuk itu, sebagai implementasi dari tantangan yang dihadapi universitas, program studi perlu mengembangkan kurikulum yang tidak hanya menekankan pada teori atau konsep, tapi juga berorientasi pada kebutuhan dunia kerja.

Faktor berikutnya adalah kurangnya riset-riset sebagai dasar untuk menganalisis kebutuhan pasar dan mahasiswa. Hal tersebut menjadi kendala karena dunia pendidikan era 4.0 menuntut lulusan yang siap kerja, sehingga perguruan tinggi perlu memiliki pandangan mengenai kebutuhan mahasiswa dan pasar yang terkini. Hal itu sejalan dengan pendapat Correia (2014) yang menyatakan bahwa pendekatan kurikulum yang berorientasi pekerjaan dapat memberi ruang peserta didik berperan sebagai mitra kerja, baik untuk perusahaan ataupun lapangan kerja yang lainnya. Pengembangan kurikulum harus disesuaikan dengan isu-isu yang sedang aktual melalui riset sebagai dasar untuk menganalisis kebutuhan pasar.

Faktor lainya yang dapat menjadi kendala prodi untuk menyiapkan lulusannya agar dapat bersaing di era revolusi industri adalah kualitas dosen. Hal itu mendukung hasil penelitian Khairiah (2015), bahwa kualltas dosen menjadi salah satu faktor utama yang menentukan keberhasilan penerapan kurikulum berbasis KKNI. Kualitas lulusan tergantung kualitas dosen-dosennya, sehingga dosen-dosen perlu mendapatkan pelatihan-pelatihan di dalam maupun luar negeri, dari pelatihan kebahasan maupun didaktik metodik. Kualitas mengajar doesen harus juga distandardisasi, dan juga dilakukan observasi secara berkala supaya kualitas perkuliahan tetap terjamin. Selain itu, kemampuan ICT dosen-dosen juga perlu diperhatikan. Dengan kemampuan ICT yang baik, dosen diharapkan mampu mengembangkan desain-desain pembelajaran teraktual misalnya blended learning.

Faktor kendala terakhir dalam implementasi kurikulum di PSPBJ adalah belum adanya patok duga (benchmarking) di bidang Deutsch als Fremdsprache. Kendala yang hampir juga ditemui dalam penelitian Siagian dan Siregar (2018), bahwa ketersedian mitra magang menjadi kendala tersendiri dalam menerapkan kurikulum berbasis KKNI. Patok duga merupakan hal yang penting untuk menjaga dan meningkatkan kinerja organisasi termasuk institusi pendidikan. Patok duga bertujuan untuk memperoleh gambaran dalam (insight) mengenai kondisi kinerja organisasi sehingga dapat mengadopsi best practice untuk meraih sasaran yang diinginkan (Amalia, 2016) Patok duga terbukti memiliki pengaruh yang signifikan dan positif terhadap kinerja organisasi/ perusahaan (Paulus dan Devi, 2013). 
Dengan demikian, PSPBJ perlu melakukan patok duga dengan institusi dan atau perguruan tinggi di Jerman di bidang Deusch als Fremdsprache. Dengan demikian, PSPBJ dapat banyak belajar dan memiliki banyak pandangan untuk meningkatkan kualitas lulusannya dan siap menyongsong tantangan kehidupan di dunia nyata.

\section{KESIMPULAN}

Dengan adanya perubahan dunia menuju tatanan dunia yang baru dan adanya perubahan peraturan-peraturan dalam dunia pendidikan, maka tuntukan perubahan kurikulum pendidikan tinggi merupakan suatu keharusan. Oleh sebab itu penyusunan dan pengembangan kurikulum setiap program studi merupakan keharusan yang harus dilakukan semua pengelola prodi. Namun demikian, terdapat kendala bagi PSPBJ UM dalam mengimplementasikan kurikulum dan kebijakan di PSPBJ UM yang sesuai dengan tuntutan lulusan di masyarakat. Faktor yang menjadi kendala dalam mengimplementasikan kurikulum PSPBJ UM, yakni (1) Standar bahasa Jerman tingkat B1 belum dilaksanakan sepenuhnya, sehingga belum semua lulusan mempunyai sertifikat bahasa Jerman tingkat B1. (2) Pengembangan kurikulum pedagogik lebih banyak menekankan pada teori/konsep. (3) Kurangnya riset-riset sebagai dasar untuk menganalisis kebutuhan pasar dan mahasiswa. (4) Kualitas dosen, khususnya di bidang ICT, dan (5) Belum adanya benchmarking di bidang Deutsch als Fremdsprache.

\section{SARAN}

PSPBJ UM perlu mempertimbangkan hasil diskusi dalam Forum Grup Discussion dan memperhatikan saran dan pendapat yang disampaikan oleh pemangku kepentingan. PSPBJ juga perlu membaca kebutuhan mahasiswa dan masyarakat agar dapat menghasilkan lulusan yang berkompeten dan siap kerja sesuai dengan tuntutan era global 4.0.

\section{DAFTAR RUJUKAN}

Amalia.2016.Benchmarking.(online),(http://dinus.ac.id/repository/docs/ajar/2016_ BPK_01_-_Kebutuhan_SMK_Baru___Amalia.pdf)

Andriani, Dwi Esti. 2010. Mengembangkan Profesionalitas Guru Abad 21 melalui Program Pembimbingan yang Efektif 4(2): hlm. 94, (Online), dalam Manajemen Pendidikan, (http://journal.uny.ac.id/index.php/jmp/article/download), diakses pada 21 Juni 2017.

Bosanquet, A.,Winchester-Seeto,T. dan Rowe, A. 2010. But I Thought You were Doing that Clarifying the Role of the Host Supervisor In ExperienceBased Learning. Asia- Pacific Journal of Cooperative Education, 13 (2): 115-134.

Correia, A. 2014. Creating Curriculum Within the Context of an Enterprise.New York: Springer.

Darling, Linda. 2006. Constructing 21st Century Teacher Education 57 (10): hlm.1, (Online), dalam Journal of Teacher Education, (http:www.chalkboardproject.org/sites/default/files/Constructing-21stCentury-Tchr- Ed.pdf), diakses pada 21 Juni 2017. 
Glaboniat, Manuela/Müller, Martin/Rusch, Paul/Schmitz, Helen/Wertenschlag, Lukas (2005): Profile deutsch : gemeinsamer europäischer Referenzrahmen; Lernzielbestimmungen, Kannbeschreibungen, kommunikative Mittel, Niveau A1-A2, B1-B2, C1-C2. Langenscheidt: Berlin/München/Wien/Zürich/New York.

Hamalik, Oemar. 2006. Manajemen Pengembangan Kurikulum. Remaja Rosdakarya: Bandung.

Hamalik, Oemar. 2007. Dasar - Dasar Pengembangan Kurikulum. Remaja Rasdakarya: Bandung.

Jono, Ali Akbar. 2016. Studi Implementasi Kurikulum Berbasis KKNI pada Program Studi Pendidikan Bahasa Inggris di LPTK se-Kota Bengkulu. Manhaj, Vol. 4, Nomor 1, Januari - April 2016

Kementerian Riset Teknologi dan Pendidikan Tinggi. 2016. Panduan Penyusunan Kurikulum Pendidikan Tinggi.

Khairiah. 2015. Pengaruh Implementasi Kurikulum Berbasis KKNI. NUANSA Vol. VIII, No. 2, Desember 2015. 171-185

Manyukhina, Yana . 2019. Learner agency and the curriculum: a critical realist perspective. The Curriculum Journal Volume 30, 2019 - Issue 3. https://doi.org/10.1080/09585176.2019.1599973

Nga, Le Tuyet. 2013. Germanistik in Vietnam. Jurnal Asosiasi Germanistik Indonesia.https://www.academia.edu/8912528/Jurnal_Asosiasi_Germanist ik_Indonesia.

Paulus, $\bar{M}$ dan Devie . 2013. Analisa Pengaruh Penggunaan Benchmarking Terhadap Keunggulan Bersaing dan Kinerja Perusahaan. BUSINESS ACCOUNTING REVIEW, VOL. 1, NO.2, 2013

Tim Kurikulum dan Pembelajaran Direktorat Pembelajaran dan Kemahasiswaan. 2014. Buku Kurikulum Perguruan Tinggi. Jakarta: Direktorat Pembelajaran dan Kemahasiswaan Direktorat Jenderal Pendidikan Tinggi Kementerian Pendidikan dan Kebudayaan.

Siagian, Beslina Afriani dan Siregar, Golda Novatrasio Sauduran. Analisis Penerapan Kurikulum Berbasis KKNI diUniversitas Negeri Medan. PEDAGOGIA : Jurnal Ilmu Pendidikan, vol 16, Desember 2018. Hal. 327342

(online),

(https://ejournal.upi.edu/index.php/pedagogia/article/view/12378)

Storc, Günther. Eichheim, Hubert. 2010. Mit Erfolg zum Zertifikat Deutsch (telc Deutsch B1): Übungsbuch+Audio-CD. Klett und langendscheidt: München.

Widodo, Pratomo. 2013. Germanistik und Deutsch Auf Lehramt in Indoensien. Paper presented on the international conference on practical experience in teaching German ("Zielsprache Deutsch - Erfahrungen aus der Unterrichtspraxis") from October 18th to 19 th, 2013 at Hanoi University, Vietnam. 